\title{
Tungsten-oxide modified silica-titania oxidative-acidic bifunctional catalyst for diol synthesis
}

\author{
Swee Ean Lim ${ }^{\mathrm{a}}$, Salasiah Che Me ${ }^{\mathrm{a}}$, Siew Ling Lee ${ }^{\mathrm{b} *}$ \\ ${ }^{a}$ Chemistry Department, Universiti Teknologi Malaysia, Johor Bahru, Malaysia \\ ${ }^{b}$ Center for Sustainable Nanomaterials, Ibnu Sina Institute for Scientific and Industrial Research, Universiti Teknologi Malaysia, 81310 UTM Skudai, \\ Johor, Malaysia \\ *Corresponding Author: sllee@ibnusina.utm.my
}

\section{Article history :}

Received 17 March 2016

Accepted 31 March 2016

GRAPHICAL ABSTRACT

\begin{abstract}
Oxidative-acidic bifunctional catalysts of tungsten oxide modified silica-titania, $\mathrm{xW}_{\mathrm{TiO}}-\mathrm{SiO}_{2}(\mathrm{x}=1,5$, $10 \mathrm{wt} \%$ ) were successfully synthesized and characterized. Both XRD and UV-Vis analyses results indicated presence of $\mathrm{WO}_{3}$ phase in samples with higher dopant amount. It also revealed tetrahedral Ti and octahedral coordinated existed as the dominant species in the samples. FTIR analysis suggested formation of Si-O-W in the tungsten oxide modified samples. The catalytic performance of the samples was evaluated via consecutive transformation of 1-octene to 1,2-octanediol through the conversion of 1,2-epoxyoctane using aqueous $\mathrm{H}_{2} \mathrm{O}_{2}$ as oxidant. While $\mathrm{TiO}_{2}-\mathrm{SiO}_{2}$ and $1 \mathrm{~W} / \mathrm{TiO}_{2}-\mathrm{SiO}_{2}$ showed no catalytic activity in yielding diol, samples $5 \mathrm{~W} / \mathrm{TiO}_{2}-\mathrm{SiO}_{2}$ and $10 \mathrm{~W} / \mathrm{TiO}_{2}-\mathrm{SiO}_{2}$ exhibited bifunctional catalytic activity. It has been demonstrated that sample $10 \mathrm{~W} / \mathrm{TiO}_{2}-\mathrm{SiO}_{2}$ was the best oxidative-acidic bifuntional catalyst which produced $321 \mu \mathrm{mol}$ 1,2-epoxyoctane and $51 \mu \mathrm{mol}$ 1,2-octanediol after $24 \mathrm{~h}$ reaction.
\end{abstract}

Keywords: Bifunctional catalyst; Oxidative; Tungsten oxide; Silica-titania

(C) 2016 Penerbit UTM Press. All rights reserved http://dx.doi.org/10.11113/mjfas.v12n1.408

\subsection{INTRODUCTION}

A large segment of the modern chemical industry is based on selective catalytic oxidation processes [1]. More than $60 \%$ of the chemicals and intermediates synthesized via catalytic processes are the products of oxidation. In the early-eighties, titanium silicalite-1 (TS-1) was first reported by Taramasso et al. in 1983 [2]. Using $\mathrm{H}_{2} \mathrm{O}_{2}$ as oxidant, TS-1 has shown great capability in oxidation and epoxidation of olefins. Silica-titania aerogel was then introduced considering its excellent catalytic properties in epoxidation [3]. Later, alternative low cost $\mathrm{SiO}_{2}$ support was employed [4]. On the other hand, acidic catalysts which include alumina, zeolites and metal oxides are also important in catalyzing reactions such as esterification and hydrolysis. These materials serve as an alternative to homogeneous acid catalysts [5]. However, monofunctional catalysts are less useful when production of certain chemicals require more than a single step. More than one reactor has to be equipped when the process is to be catalyzed by different catalysts.

As such, bifunctional catalysts are developed to overcome the problem. Bifunctional catalysts consist of two different active sites which are capable of catalyzing two different reactions in a single material. A bifunctional catalyst with oxidative and acidic sites could aid in diols formation from alkene though epoxidation and subsequent hydrolysis. Indeed, diols serve as important feedstocks in fine chemistry as well as intermediates for agrochemicals [6]. Diols contribute to high water solubility, hygroscopicity and reactivity with many organic compounds. Presently, the production of diols involves dual steps of reaction in separate chambers. As such, high cost production is involved and the process is timeconsuming. In view of this, an effective bifunctional catalyst is needed for rapid production of diols at a lower cost.

One of the vital challenges is to design a highly effective catalyst combining oxidative and acidic properties. In the past decades, various oxidative-acidic bifunctional catalysts have been reported. Prasetyoko et al. [7] had initiated the design of an oxidative-acidic bifunctional catalyst by using sulphated zirconia loaded on TS-1. Even so, only samples with high loading of sulfated zirconia showed catalytic activity towards transformation of 1-octene to 1,2-octanediol through 1,2-epoxyoctane. It was claimed that metal oxides such as $\mathrm{V}, \mathrm{Mo}, \mathrm{W}$ and $\mathrm{Nb}$ could act as redox centers and their presence had influenced formation of both Lewis and Brønsted acidity sites on various supports [8]. This was evidenced in previous studies using vanadium and niobium oxides as modifier for silica-titania $[9,10]$.

Silica-titania has been evidenced as a good catalyst for epoxidation owing to the highly dispersion of $\mathrm{Ti}^{4+}$ 
species in the catalyst, which corresponds to Lewis acidity [11] Nevertheless, Brønsted acidity is needed for transformation of diols from epoxides. As such, vanadium and niobium oxides were loaded on silica-titania in conjunction of generating Brønsted acidity. However, the performance is less satisfactory in terms of selectivity and yield of diols.

Due to similar properties of transition metals in Group 5 and 6, tungsten oxide was selected as modifier for $\mathrm{TiO}_{2}$ to enhance the formation of both oxidative and acidic sites on catalysts. Although catalyst which contains tungsten oxide had been synthesized using titanium-silicate (TS-1) as support reported in Prasetyoko et al. [12], the amount of Brønsted acid formed as well as catalytic activity did not increase significantly with even at very high tungsten loading. As such, it is worth to explore the effect of impregnation of tungsten oxide using a different support, which is silica-titania.

\subsection{EXPERIMENTS}

\subsection{Synthesis of bifunctional catalysts}

$\mathrm{SiO}_{2}-\mathrm{TiO}_{2}$ with molar ratio of $\mathrm{Si}: \mathrm{Ti}=33: 1$ was synthesized via sol-gel method as described elsewhere [9,13]. A mixture of tetraethylorthosilicate (TEOS, Alrich, 99.8\%), ethanol (EtOH), $\mathrm{H}_{2} \mathrm{O}$ and $\mathrm{HNO}_{3}$ was stirred at room temperature for 30 minutes. Later on, a mixture containing titanium(IV) isopropoxide (TTIP, Aldrich, 97\%). EtOH and acetylacetone was added into previously prepared solution and stirred under the same condition. Subsequently, the mixture was dried at $353 \mathrm{~K}$ until a clear gel was obtained. The resulting wet gel was dried at $383 \mathrm{~K}$ overnight and calcined at $773 \mathrm{~K}$ for $5 \mathrm{~h}$ to yield $\mathrm{TiO}_{2}-\mathrm{SiO}_{2}$ powder.

Tungsten oxide was wet impregnated on $\mathrm{TiO}_{2}-\mathrm{SiO}_{2}$ powder. In conjunction of this, $x$ wt $\%$ of $\mathrm{W}$ was prepared by dissolving sufficient amount of ammonium tungstate pentahydrate $\left(\mathrm{NH}_{4}\right)_{10} \mathrm{~W}_{12} \mathrm{O}_{41 .} 5 \mathrm{H}_{2} \mathrm{O}$ (Qrec, 99.99\%) in 10 $\mathrm{mL}$ of $\mathrm{H}_{2} \mathrm{O}$. The mixture was stirred vigorously at room temperature for $1 \mathrm{~h}$, followed by drying at $383 \mathrm{~K}$ overnight. The obtained solid was ground and calcined at $773 \mathrm{~K}$ for 5 h. The resulted material was denoted as $x \mathrm{~W} / \mathrm{TiO}_{2}-\mathrm{SiO}_{2}$ (where $\mathrm{x}=1,5,10 \mathrm{wt} \%$ ).

\subsection{Characterization}

The crystal structure and crystallinity of the catalyst was determined with X-ray diffraction (XRD) recorded on a powder diffractometer (Bruker Advance D8, $40 \mathrm{kV}, 40$ $\mathrm{mA}$ ) using a $\mathrm{Cu} \mathrm{K} \alpha$ radiation source in the range of $2 \theta=10$ $-60^{\circ}$.

In order to investigate $\mathrm{Ti}$ and $\mathrm{W}$ species formed in the synthesized materials, diffused reflectance UV spectroscopy analysis was carried out using Perkin Elmer
Lambda 900 DRUV/Vis spectrometer. The samples were scanned over the range from 200 to $800 \mathrm{~nm}$.

Infrared measurements were performed using a Thermo Scientific Nicolet iS10 FT-IR spectrometer using $\mathrm{KBr}$ pellet technique to identify the type of bonding present in the materials. The spectra were recorded in the region of $400-4000 \mathrm{~cm}^{-1}$ using a spectral resolution of $2 \mathrm{~cm}^{-1}$.

\subsection{Catalytic testing}

The catalytic performance of tungsten oxide modified samples was evaluated through the consecutive formation of 1,2-octanediol via transformation of 1,2epoxyoctane from 1-octene. The reaction mixture containing 1-octene (15 mmol, Merck, 97\%), $\mathrm{H}_{2} \mathrm{O}_{2}$ (30 mmol, Merck, $30 \%)$ in acetonitrile (10 mL, Merck, 99.9\%) was placed in a round bottom flask equipped with a condenser. The reaction was carried out in an oil bath at $343 \mathrm{~K}$ for $24 \mathrm{~h}$ under stirring condition. The products of the reaction were analyzed on a Shimadzu GC 2014 chromatograph using a HP-5 column.

\subsection{RESULTS AND DISCUSSION}

\subsection{Physical properties}

$\mathrm{TiO}_{2}-\mathrm{SiO}_{2}$ synthesized was light and fluffy powder even after calcination at $773 \mathrm{~K}$ for $5 \mathrm{~h}$. Colour changes were observed in tungsten oxide loaded samples: $x \mathrm{~W} / \mathrm{TiO}_{2}-\mathrm{SiO}_{2}$ changed from white to yellow and increase in colour intensity with higher tungsten loading.

Figure 1 shows the X-ray diffractograms of the synthesized materials. XRD pattern indicated that $\mathrm{TiO}_{2}$ $\mathrm{SiO}_{2}$ was an amorphous material. Similar finding was reported previously [10]. No characteristic peak corresponds to $\mathrm{TiO}_{2}$ was observed, indicating that $\mathrm{TiO}_{2}$ was highly dispersed on the surface of $\mathrm{SiO}_{2}$, or were incorporated into $\mathrm{SiO}_{2}$ framework. A broad peak at a low diffraction angle from $20^{\circ}$ to $30^{\circ}$ corresponds to the amorphous-state $\mathrm{SiO}_{2}$ shells surrounding tungsten-sulphate [13]. For species loaded with tungsten oxide, small peak was observed at $2 \theta=23.1^{\circ}$ for 5 and $10 \mathrm{wt} \%$ tungsten loaded samples. This peak was indexed to monoclinic $\mathrm{WO}_{3}$ (JCPDS 43-1035), indicating presence of crystalline $\mathrm{WO}_{3}$ in the samples as a result of heat treatment. Interestingly, the peak intensity of $\mathrm{WO}_{3}$ of $10 \mathrm{~W} / \mathrm{TiO}_{2}-\mathrm{SiO}_{2}$ was lower than that of $5 \mathrm{~W} / \mathrm{TiO}_{2}-\mathrm{SiO}_{2}$. This could be due to lower sample amount of $10 \mathrm{~W} / \mathrm{TiO}_{2}-\mathrm{SiO}_{2}$ used in the XRD analysis. Notably, the XRD pattern of the samples showed only a small peak with low intensity. A possible explanation to this is due to amorphous nature of silicatitania. This also indicates tungsten species were distributed homogeneously throughout the support material [14]. 


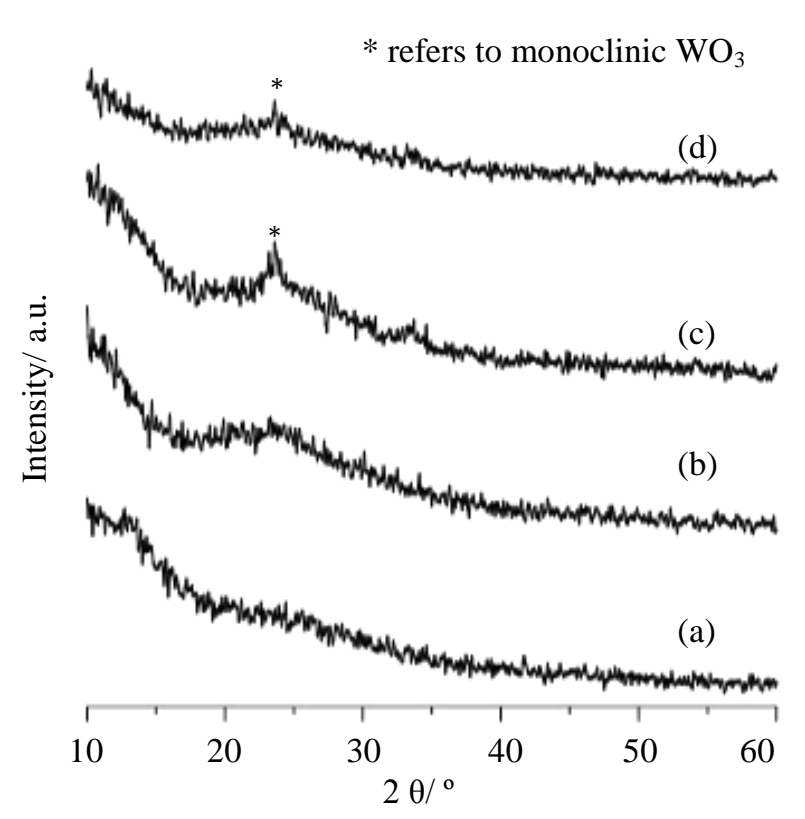

Fig. 1 XRD patterns of (a) $\mathrm{TiO}_{2}-\mathrm{SiO}_{2}$, (b) $1 \mathrm{~W} / \mathrm{TiO}_{2}-\mathrm{SiO}_{2}$, (c) $5 \mathrm{~W} / \mathrm{TiO}_{2}-\mathrm{SiO}_{2}$ and (d) $10 \mathrm{~W} / \mathrm{TiO}_{2}-\mathrm{SiO}_{2}$

Figure 2 depicts DRUV-Vis spectra of the samples. As can be seen, there was only a major peak at around 270 nm for $\mathrm{TiO}_{2}-\mathrm{SiO}_{2}$, which is associated to tetrahedrally coordinated $\mathrm{Ti}$ species. Indeed, tetrahedral $\mathrm{Ti}$ species is widely acknowledged as the most important $\mathrm{Ti}$ species to provide active site for oxidation reaction. This electronic transition was assigned to a charge transfer of tetrahedral $\mathrm{Ti}$ sites between $\mathrm{O}^{2-}$ and the central Ti(IV) atom [10]. Meanwhile, the peak observed at around $300 \mathrm{~nm}$ in $x \mathrm{~W} / \mathrm{TiO}_{2}-\mathrm{SiO}_{2}(x=1,5,10 \mathrm{wt} \%)$ was linked to the creation of octahedral or polymeric $\mathrm{Ti}$ species. A possible explanation to this is some tetrahedral $\mathrm{Ti}$ framework was transformed into octahedral structure after impregnating with tungsten oxide. The intensity of this peak increased with higher loading of tungsten. The broad band at around $400 \mathrm{~nm}$ as observed in materials modified with tungsten oxide was associated to $\mathrm{O}^{2-} \rightarrow \mathrm{W}^{6+}$ charge transfer transition, as in the case of monoclinic $\mathrm{WO}_{3}[15]$. This also explains the appearance of pale yellow colour of the samples. This transformation of some tetrahedral $\mathrm{Ti}$ framework to octahedral structure is due to the presence of the acid [13].

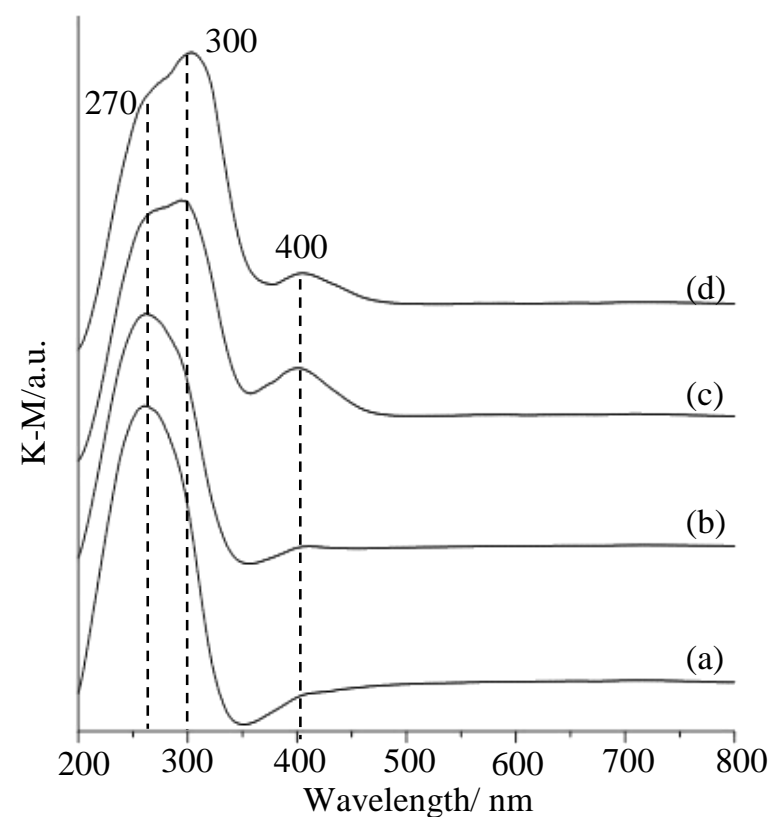

Fig. 2 DRUV-Vis spectra of (a) $\mathrm{TiO}_{2}-\mathrm{SiO}_{2}$, (b) $1 \mathrm{~W} \mathrm{TiO}_{2}-$ $\mathrm{SiO}_{2}$, (c) $5 \mathrm{~W} / \mathrm{TiO}_{2}-\mathrm{SiO}_{2}$ and (d) $10 \mathrm{~W} / \mathrm{TiO}_{2}-\mathrm{SiO}_{2}$

FTIR spectra of samples (Figure 3) show typical silicate absorptions at 466 and $1100 \mathrm{~cm}^{-1}$ that were associated to $\mathrm{Si}-\mathrm{O}-\mathrm{Si}$ bending and stretching vibrations respectively [16]. The peak at $799 \mathrm{~cm}^{-1}$ is corresponded to $\mathrm{Si}-\mathrm{O}-\mathrm{Ti}$ or Si-O-W bond. As can be seen (Fig. 3 (b-d), the tungsten oxide loading affected the formation of the bondings. Meanwhile, the peak at $970 \mathrm{~cm}^{-1}$ was linked to surface $\mathrm{Si}-\mathrm{OH}$ vibrations and possibly overlaps absorptions of Si-O-Ti bond [17]. Apart from that, a broad band at $3450 \mathrm{~cm}^{-1}$ and a small peak at $1650 \mathrm{~cm}^{-1}$ were attributed to stretching and bending frequency of hydroxyl groups, respectively. As compared among the tungsten oxide modified samples, the intensity of these two bands increased with the increase of $\mathrm{W}$ content in the sample. This may imply higher loading of $W$ enhanced hydrophilicity property of the resulted materials. Surprisingly, no typical band of $\mathrm{W}=\mathrm{O}$ or $\mathrm{O}-\mathrm{W}-\mathrm{O}$ was observed. In the literature [18], $\mathrm{W}=\mathrm{O}$ and $\mathrm{O}-\mathrm{W}-\mathrm{O}$ band could be detected at $962 \mathrm{~cm}^{-1}$. Possibly, these bands were overshadowed by $\mathrm{Si}-\mathrm{OH}$ and $\mathrm{Si}-\mathrm{O}-\mathrm{Ti}$ stretching frequency. 


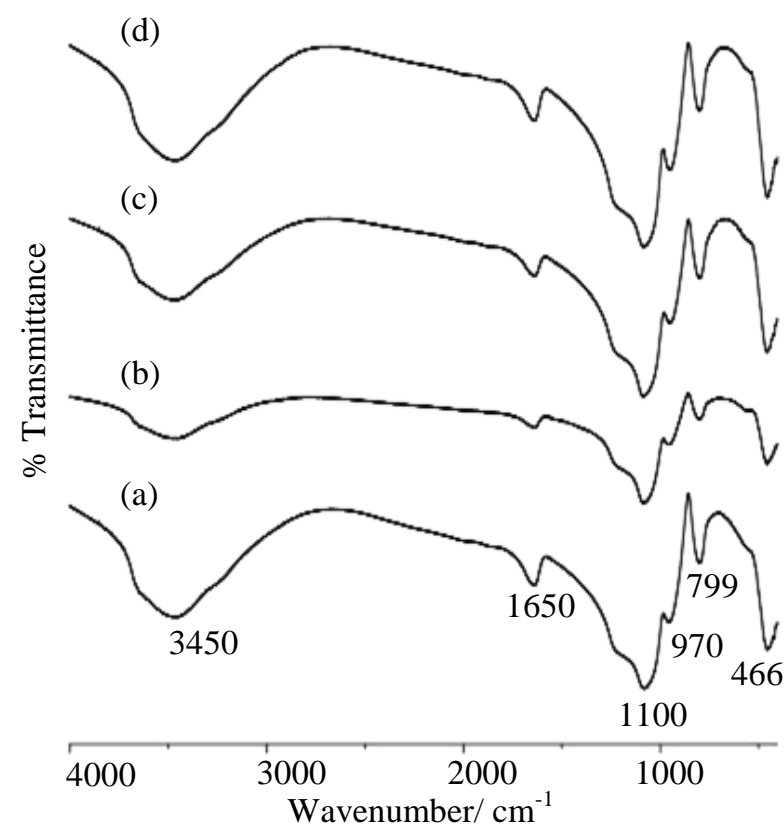

Fig. 3 FTIR spectra of (a) $\mathrm{TiO}_{2}-\mathrm{SiO}_{2}$, (b) $1 \mathrm{~W} / \mathrm{TiO}_{2}-\mathrm{SiO}_{2}$, (c) $5 \mathrm{~W} / \mathrm{TiO}_{2}-\mathrm{SiO}_{2}$ and (d) $10 \mathrm{~W} / \mathrm{TiO}_{2}-\mathrm{SiO}_{2}$

\subsection{Catalytic performance}

The evaluation of catalytic performance was conducted at $343 \mathrm{~K}$ for $24 \mathrm{~h}$ through the consecutive transformation of 1-octene to 1,2-octanediol via the formation of 1,2-epoxyoctane using $\mathrm{H}_{2} \mathrm{O}_{2}$. Traces of 1,2epoxyoctane $(80 \mu \mathrm{mol})$ and no 1,2-octanediol were detected in $\mathrm{TiO}_{2}-\mathrm{SiO}_{2}$ catalyzed reaction. After impregnation of $1 \mathrm{wt} \% \mathrm{~W}$, sample $1 \mathrm{~W} / \mathrm{TiO}_{2}-\mathrm{SiO}_{2}$ produced higher yield of 1,2-epoxyoctane $(104 \mu \mathrm{mol})$, without formation of any 1,2-octanediol. The results strongly suggested that $\mathrm{TiO}_{2}-\mathrm{SiO}_{2}$ served merely as a weak oxidative site for epoxidation. Apparently, the tungsten oxide modification has promoted the oxidative active site generation or has strengthened the oxidative active sites.

Further increased amount of $\mathrm{W}$ dopant has increased the yield of 1,2-epoxyoctane. Samples $5 \mathrm{~W} / \mathrm{TiO}_{2}-\mathrm{SiO}_{2}$ and $10 \mathrm{~W} / \mathrm{TiO}_{2}-\mathrm{SiO}_{2}$ produced 168 and $132 \mu \mathrm{mol} 1,2-$ epoxyoctane, respectively. Interestingly, formation of 1,2octanediol was detected in the reactions which were catalyzed using these two samples. The results strongly indicated that these samples were bifunctional catalysts to produce diol from alkene via single step reaction. The detection of the diol strongly implied the presence of Brønsted acid sites in the samples since only Brønsted acidity provides the active site for epoxy to diol transformation [10].
The current results suggested that $10 \mathrm{~W} / \mathrm{TiO}_{2}-\mathrm{SiO}_{2}$ was the best oxidative-acidic bifunctional catalyst to produce $51 \mu \mathrm{mol} 1,2$-octanediol after the reaction. In the literature, niobium oxide modified $\mathrm{TiO}_{2}-\mathrm{SiO}_{2}$ was a weak catalyst in epoxidation reaction as it only produced 59 $\mu \mathrm{mol}$ 1,2-epoxyoctane, without any yield of 1,2-octanediol after $24 \mathrm{~h}$ reaction [10]. Therefore, it could be concluded that tungsten oxide might be a better modifier than niobium oxide in an oxidative-acidic bifunctional catalyst design.

Table 1 Product yields of $\mathrm{TiO}_{2}-\mathrm{SiO}_{2}$ and $\mathrm{xW} / \mathrm{TiO}_{2}-\mathrm{SiO}_{2}$ samples in transformation of 1-octene to 1,2-octanediol through formation of 1,2-epoxyoctane at $343 \mathrm{~K}$ for $24 \mathrm{~h}$.

\begin{tabular}{lcc}
\hline Catalyst & $\begin{array}{c}\text { Yield of 1,2- } \\
\text { epoxyoctane } \\
\mu \text { mol })\end{array}$ & $\begin{array}{c}\text { Yield of 1,2- } \\
\text { octanediol ( } \\
\mu \text { mol })\end{array}$ \\
\hline $\mathrm{TiO}_{2}-\mathrm{SiO}_{2}$ & 80 & 0 \\
$1 \mathrm{~W} / \mathrm{TiO}_{2}-\mathrm{SiO}_{2}$ & 104 & 0 \\
$5 \mathrm{~W} / \mathrm{TiO}_{2}-\mathrm{SiO}_{2}$ & 168 & 44 \\
$10 \mathrm{~W} / \mathrm{TiO}_{2}-\mathrm{SiO}_{2}$ & 321 & 51 \\
\hline
\end{tabular}

\subsection{CONCLUSION}

New tungsten oxide impregnated silica-titania oxidative-acidic bifunctional catalysts have been successfully synthesized. Tetrahedrally coordinated $\mathrm{Ti}$ species acted as active oxidative sites. Presence of tungsten oxide was believed to strengthen the oxidative sites. Besides, introduction of $5 \mathrm{wt} \%$ or more $\mathrm{W}$ has generated Brønsted acidity in the samples. The results showed that sample $10 \mathrm{~W} / \mathrm{TiO}_{2}-\mathrm{SiO}_{2}$ was a good oxidative-acidic bifunctional catalyst to produce $321 \mu \mathrm{mol} 1,2$-epoxyoctane and $51 \mu \mathrm{mol} 1,2$-octanediol at $343 \mathrm{~K}$ for $24 \mathrm{~h}$.

\section{ACKNOWLEDGEMENTS}

The authors express gratitude to the Ministry of Higher Education (MOHE), Malaysia and Universiti Teknologi Malaysia for Research University Grants (Q.J130000.2426.03G35 and Q.J130000.2609.10J66).

\section{REFERENCES}

(1) G. Centi, F. Cavani, and F. Trifirò,. 2001. (1st ed.) New York: Kluwer Academic/Plenum Publishers. 143-201

(2) M. Taramasso, G. Perego, and B. Notari, 1983. Washington DC: U.S. Patent and Trademark Office. U.S. Patent No. 4,410,501.

(3) M. Reiche, E. Ortelli, and A. Baiker, 1999. Appl. Catal. B: Envi. 23(2): 187-203.

(4) L. Yuliati, H. Itoh, and H. Yoshida, 2006. Stud. Surf. Sci. and Catal. 162: 961-968.

(5) D. Prasetyoko, 2006. Doctoral Dissertation. Universiti Teknologi Malaysia, Skudai.

(6) M. Beller, C. Döbler, G. Mehltretter, and U. Sundermeier, 2004. U.S. Patent No. 6,825,377. Washington DC: U.S. Patent and Trademark Office. 
(7) D. Prasetyoko, Z. Ramli, S. Endud, and H. Nur, 2005. J. Mol. Catal. A: Chem. 241(1): 118-125.

(8) J. Macht, and E. Iglesia, 2008. Phy. Chem. Chem. Phy. 10(35): 53315343.

(9) S. L. Lee, S. C. Wei, H. Nur, and H. Hamdan, 2010. Int. J. Chem. React. Eng. 8(1): 1-13.

(10) J. M. Ekhsan, S. L. Lee, and H. Nur, 2014. Appl. Catal. A: Gen. 471: $142-148$.

(11) S. Hu, R. J. Willey, and B. Notari, 2003. J. Catal. 220(1): 240-248.

(12) D. Prasetyoko, H. Fansuri, Z. Ramli, S. Endud, and H. Nur, 2009. Catal. Lett. 128(1-2): 177-182.
(13) S. Che Me, H. Nur, and S. L Lee, 2015. Malay. J. Fund. Appl. Sci. 11(3): 122-125.

(14) F. Adam, and A. Iqbal, 2011. J. Chem. Eng. 171(3), 1379-1386.

(15) G. Ramis, C. Cristiani, A. S. Elmi, P. Villa, and G. Busca, 1990. J. Mol. Catal, 61(3), 319-331.

(16) M. C. Capel-Sanchez, J. M. Campos-Martin, and J. L. G. Fierro, 2003. Appl Catal. A: Gen, 246(1): 69-77.

(17) S.L. Lee, H. Nur, P.W. Koh, J.M. Ekhsan, S. C. Wei. 2011. Int. J Appl. Phys. Math. 1: 43-47

(18) D. Reyes, V. D. Garcia, A. P. Benitez and J. A. Balderas. Lopez. 2008. Soc. Mex. Cie. Tecn. Super. Mat. 21(2) 12-17 